\title{
On the influence of sonorous vibrations upon the radiometer
}

\section{J. Jeannel}

To cite this article: J. Jeannel (1876) On the influence of sonorous vibrations upon the radiometer, Philosophical Magazine Series 5, 2:11, 320-320, DOI: 10.1080/14786447608639114

To link to this article: http://dx.doi.org/10.1080/14786447608639114

曲 Published online: 13 May 2009.

Submit your article to this journal $\pi$

Џll Article views: 2

Q View related articles $\sqsubset$ 
$\mathrm{SiO}_{2} 38 \cdot 40, \mathrm{AlO}_{3} 2 \cdot 80, \mathrm{FeO} 15 \cdot 52,\left(\mathrm{MgO} 39 \cdot 88\right.$, $\mathrm{H}_{2} \mathrm{O} 3 \cdot 40=100$. -Silliman's American Journal, September 1876.

\section{ON THE INFLUENCE OF SONOROUS VIBRATIONS UPON THE RADIOMETER. BY J. JEANNEL.}

I have ascertained that the rotatory movements of the radiometer can be determined by certain sonorous vibrations. In regard to this I have, in conjunction with M. Coulier and M. Alvergniat, made various experiments, of which $I$ think $I$ ought to render an account to the Academy.

In semiobscurity three radiometers $\mathrm{A}, \mathrm{B}, \mathrm{C}$, of unequal sensitiveness and at perfect rest, were placed on the inner shelf of a saloon-organ. The bass notes (those of the first three octaves) determined the rotation-movements. The deepest bass notes have the greatest action; nevertheless the $f a$ and the $f a$ sharp of the lower octave, especially with the bourdon stop, produce the most rapid rotation. $U t, r e$, and $m i$, though deeper, have much less action.

The radiometers do not all behave in the same way as regards the speed and the direction of their rotations. Thus, through the effect of $f a$ or $f a$ sharp of the lower octave, radiometer $A$ (the least sensitive to light) rotates with the velocity of about one turn per second, with the black faces of the vanes in front-that is to say, the inverse of the motion produced by light; $\mathrm{B}$ and $\mathrm{C}$ (more sensitive to. light) turn more slowly, and in the direction of the light-produced motion, viz. with the bright faces in front.

These facts I propose to explain thus. As certain notes produce no effect, it is evident that the needle which forms the internal support of the revolving arms must be able to vibrate in unison with the notes of the organ in order that the rotatory movement may be produced. Certain vibrations of the organ-shelf, transmitted to the needle, communicate to it circular or angular vibrations, from which results the rotation of the arms which it supports. What appears to demonstrate that this explanation is well founded is, that on pressing the soft part of the finger upon the top of the radiometer we prevent it from vibrating, and, at the same time, from turning.

The shelf of a piano produces similar effects, but in a less degree.

When the above experiments are tried in a medium where the diffused light is nearly sufficient to start the radiometer, even the feeblest deep sounds determine the rotation in the usual direction: the roll of the rehicles is sufficient.

Here the explanation presents itself to the mind spontaneously. The arms undergo the impulsion of the force which is to put them in motion; but this force is counterbalanced by the friction of the top piece upon the point of the needle; no motion can take place. But if the vibrations interpose, the top piece, raised above the needle-point and thus removed from friction during a certain space of time, can obey the impulse. Hence it results that under the influence of the vibrations the radiometer appears much more sensitive to light than when it is at rest.-Comptes Rendus de l'Académie des Sciences, vol. lxxxiii. p. 445. 